\title{
İslâm Dünyasında Hastaneler
}

Hospitals in the Islamic World

Samet Şenel

iSakarya Üniversitesi Sosyal Bilimler Enstitüsü İslam Tarihi ve Sanatları Doktora Öğrencisi https://orcid.org/0000-0003-1909-170X

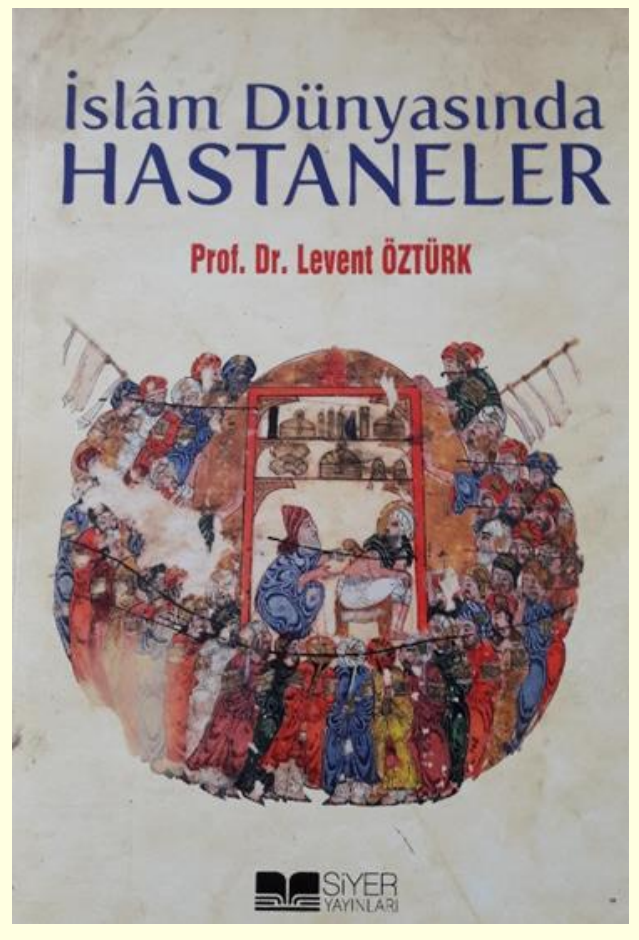

İslâm Dünyasında Hastaneler

Prof. Dr. Levent ÖZTÜRK

İstanbul: Siyer Yayınları, 2018, 279 sayfa.

ISBN 978-605-2375-61-7

\section{Sayın Editör;}

Prof. Dr. Levent ÖZTÜRK, 22.09.1964'de Bursa'da doğdu. Tekirdağ, Gebze-Darıca ve Nazilli'de bulundu. 1986'da Marmara Üniversitesi İlahiyat Fakültesi'nden mezun oldu. Hz. Muhammed'in Habeşistan'la Münasebetleri adlı yüksek lisans tezini Prof. Dr. Mustafa Fayda'nın yönetiminde tamamladı. 1988 yılında doktora çalışmasına başlayan Levent Öztürk, aynı zamanda 1989 Ocağından 1993 Ağustosuna kadar İstanbul Özel Doğuş Lisesi'nde Din Kültürü ve Ahlak Bilgisi öğretmenliği yaptı. Şubat 1995'de, Prof. Dr. Mustafa Fayda yönetiminde sürdürdüğü Haçlı Seferleri'ne Kadar Abbâsîler Döneminde Hristiyanlar konulu çalışmasıyla doktor unvanına lâyık görüldü. 1993-1994 yılları arasında Süleyman Demirel Üniversitesi

*Lokman Hekim Dergisi, 2019; 9(1):1-5

DOI: 10.31020/mutftd.500945

e-ISSN: 1309-8004

Geliş Tarihi - Received:22 Aralık 2018; Kabul Tarihi - Accepted: 11 Ocak 2019

Iletişim - Correspondence Author: Taha Ayyıldız <obirtahadir@hotmail.com> 
İlahiyat Fakültesi'nde çalıştı. 1997'de Sakarya Üniversitesi İlahiyat Fakültesi'ne naklen atandı. İslâm Tarihi Bilim Dalı'nda 6 Mayıs 2002' de doçent, 21 Eylül 2007'de profesör unvanına yükseltildi. Halen i̇slâm Tarihi ve Sanatları Bölüm Başkanlığı vazifesini sürdürmekte olan Levent Öztürk, evli ve iki çocuk babasıdır. Kitap, makale, bildiri ve çevirilerden müteşekkil basıı yüze yakın bilimsel çalışması olan yazarın İslâm Toplumunda Hristiyanlar, Câhiliye Arapları, Hz. Peygamber Döneminde Sağlık Hizmetlerinde Kadınların Yeri, Tarih Felsefesi, İslâm Tıp Tarihi Üzerine İncelemeler, İslâm Dünyasında Hastaneler ve Illk Hicret Habeşistan adlı yayımlanmış kitap çalışmaları bulunmaktadır.

\section{Giriş}

İslâm Tarihi alanında yaptığı çalışmalarla tanınan Levent Öztürk, Hz. Peygamber Döneminde Sağlık Hizmetlerinde Kadınların Yeri, İslâm Tıp Tarihi Üzerine İncelemeler başlıklı kitaplarıyla tıp tarihine de katkı sağlayan önemli eserlere imza atmış bir araştırmacıdır. Levent Öztürk, "Haçlı Seferleri'ne kadar Abbâsîler döneminde Hristiyanlar" başlı̆ını taşıyan doktora tezini 1994 yılında tamamlamıştır (İslâm Toplumunda Hristiyanlar, İstanbul 1998, 2012). Tezinin önemli başlıklarından birisi Hristiyan hekimlerin İslâm toplumuna sundukları bilimsel katkılardır. Doktora tezinin izinde ürettiği makale ve kitap çalışmalarına bakılacak olursa ilk dönem İslâm dünyasındaki tıbbî faaliyetler üzerine yoğunlaştığı anlaşılan Öztürk'ün tıp tarihine katkı sağlayan önemli eserlerinden birisi de tanıtımını yapmak istediğimiz İslâm dünyasında inşa edilen hastanelerle ilgili monografik çalışmasıdır.

İncelediğimiz bu eser, ilk defa 2007 yılında "On İkinci Yüzyıla Kadar İslâm Dünyasında Hastaneler" başlı̆ıyla İz yayıncılık tarafından yayımlanmıştır. İkinci basımı ise Siyer yayınlarında "İslâm Dünyasında Hastaneler" adıyla 2018 yılında okuyucuların istifadesine sunulmuştur. Öztürk, çalışmasında ilk hastanenin ne zaman kurulduğu hakkında kapsamlı bir araştırma yapmış ve on ikinci yüzyıla kadar nerelerde hastane inşa edildiği hakkında önemli açıklamalarda bulunmuştur.

Türkçe literatürde İslâm'ın başlangıcından miladî on ikinci asra kadar kurulan hastaneler hakkında birkaç makale kaleme alınmış ise de Öztürk'ün çalışması bu konudaki ilk monografik kitap çalışmasıdır. Bu kurumla ilgili daha çok Eyyûbîler ve sonrası dönemlerde oluşturulan hastaneler araştırılmıştır. İngilizcede yazarın incelemiş olduğu zamanaralığıyla (610-1100) alakalı birçok çalışma bulunmaktadır. Nitekim bu dönem aralığını inceleyen kişiler arasında Michael W. Dols, Oliver Kahl, Peter Pormann ve Ahmed Ragab isimleri zikredilebilir. Arapça literatürde ise Ahmed Îsâ ve Mes'ûd Saîd, hastanelerle alakalı önemli çalışmalar kaleme almıştır. Ancak bu eserlerde çoğu zaman konuyla ilgili materyallerin tartışılmadan zikredildiği, derinlemesine ve irdeleyici bir inceleme gerçekleştirilemediği görülmektedir. Buna tarihsel malzemenin yanlış kullanımını da ilave etmek gerekir.

\section{İslâm Dünyasında Hastaneler: Tanıtım ve Değerlendirme}

Levent Öztürk'ün çalışması giriş, sonuç dışında iki bölüm ve ekler kısmından oluşmaktadır. Giriş, ikiye ayrılmakta, ilk olarak kaynak ve araştırmalar hakkında bilgiler verilmekte ikincisinde ise kadim medeniyetlerde sağlık hizmeti veren mekânlar aktarılmaktadır. Kaynak ve araştırmalar başlığında klasik eserler kronoloji takip edilmeden içerdikleri bilgi değerlerine göre tanıtılmakta akabinde ise modern araştırmalarda bilim tarihiyle alakalı malumatın, medeniyetlerin diğer toplumlara karşı üstünlük kurma adına bilerek veya farkında olmadan çarptırılmasından dolayı karşılaşılan hatalar vurgulanmaktadır.

Girişte ikinci olarak kadim medeniyetlerin sağlık hizmetlerinde bulundukları yerlerden bahseden Öztürk, ilk insanların mağara, kâhin evleri ve tapınaklarda hizmet gördüklerini zikrettikten sonra Mezopotamya medeniyetinden başlayarak Mısır, Hint, Türk, Yunan, Roma, Bizans, Arap medeniyetlerindeki sağlık hizmetlerinden bahsetmektedir. Burada yazar, Fars medeniyetindeki sağlık hizmetlerini müstakil bir başık altında ele almamış Mezopotamya medeniyeti altında incelemiştir. 
Yazar, Mezopotamya'da sağlık hizmetlerinin gerçekleştirildiği yerlerden birinin tapınaklar olduğunu ve bu durumun diğer medeniyetlerde de karşımıza çıktığını aktarmakta hemen ardından bir bilim merkezi olan Cündîşâpûr'un kurulması ve buradaki hastanenin faaliyetine dair genel problemleri tartışmaktadır. Öztürk, tartışmaların sonucunda eldeki mevcut bilgilerden hareketle hastanenin altıncı asırda kurulmuş olabileceği fikrinin daha baskın olduğunu düşünmektedir. Fakat bu tetkiklerin neticesinde yazar kendisi ile çelişecek bir şekilde Cündîşâpûr'daki hastanenin i̇slâm fetihlerinden üç asır önce mevcut olduğunu düşündürecek bir cümleye de eserinde yer vermektedir (s. 23-31).

Levent Öztürk, incelemede bulunmuş olduğu diğer medeniyetlerin her birini kendi içerisinde sağlık hizmetlerinde bulunulan yerlerle alakalı bir kronolojiye tabi tutarak incelemiştir. Ayrıca bu kadim medeniyetlerle alakalı bilgileri sunarken arkeolojik çalışmalardan da istifade etmiştir. Mısır medeniyetinde tapınaklarda ve İskenderiye okulunda, Hintlilerde tapınaklarda, Türklerde dağ tepelerinde, özel çadırlarda, mabetlerde, Budist dinine inanan Türklerde ise Vihara (Nevbahar) denilen manastırlarda tıp hizmeti verilmektedir. Yunanlıların bir yandan milattan önce yedinci yüzyıldan itibaren Asklepion olarak ün kazanacak panteonlarda diğer yandan da Circuitores adı verilen gezgin hekimler vasıtasıyla tıp hizmeti sundukları Roma medeniyetinde ise Asklepionların yanında askeri hastanelerde, özel hekimlere ait evlerde, muayenehanelerde veya hastaların kendi evlerinde sağlık hizmeti verdikleri anlaşılmaktadır.

Bizans'ta, Hristiyanlığın kabulüyle beraber Roma'nın iyileştirici rolünü temsil eden şifa tanrıları yerine Hristiyan azizler bu görevi üstlenmişlerdir. Sağlık mekânları olan Asklepionlar yıkılmış, bunların yerini kilise ve manastırlar almıştır. Ayrıca burada sağlık hizmeti alanında nosocomium (hastane) olarak zikredilen kurum mevcuttur. Bu nosocomiumun günümüzdeki hastane kavramına benzediği anlaşılmakta doğu ve batı Bizans dünyasında birçok yerde bulunmaktadır.

Kadim medeniyetlerden son olarak Arapları ele alan yazar, onların genelde folklorik tedavi ile ilgilenip putlara taparak iyileşmeye çalıştıklarını ayrıca kâhinler, arrâflar, kadınlar, tecrübeli savaş̧̧ılar ve Cündîşâpûr gibi bölgelerde eğitim görmüş bazı kimselerin sağlık hizmetinde bulunduklarını aktarmaktadır. Son olarak bedevilerin sağlık hizmetinde kendi çadırlarını kullandıklarını tedavi olunamayacak derecede ise şehirlere gidip orada hizmet aldıklarını dile getirmektedir.

Levent Öztürk, birinci bölümde İslâm dünyasında sağlık hizmeti veren mekânlar ve ilk hastanenin ortaya çıkışını ele almıştır. Bu bölümü de iki alt başlığa ayırarak birinci kısımda İslâm dünyasında sağıık hizmeti veren mekânları incelemiş, ikinci kısımda ise İslâm dünyasında ilk hastanenin ortaya çıkışı problemini izah etmeye çalışmıştır.

Birinci kısımda yazar, İslâm dünyasında sağlık hizmeti veren mekânların coğrafî genişlik ve uzun bir sürecin ele alınmasından dolayı problemli olduğunu bu durumun özel bir çalışmayla yeniden incelenmesi gerektiğini vurgulamaktadır. Öztürk, ilk olarak sabit ve seyyar çadırlar, manastırlar, halife ve devlet erkânının sarayı, hekim evleri, hekim dükkânları, hastane evleri, hamamlar ve son olarak gezici hekimlerin mekânı olan sokakların sağlık hizmetlerinde kullanıldığını belirtmiş akabinde bunların her birini ayrı ayrı açıklamıştır.

Yazar, sabit ve seyyar çadırlardan bahsederek bunların bedevi Araplarda ve yerleşik Araplarda mevcut folklorik bir tedavi yeri olduğunu belirtmektedir. 0 , günümüzdeki pek çok araştırmacının sıklıkla kaleme aldığı üzere Rüfeyde'nin çadırını ilk hastane olarak ele almanın yanlışlığı üzerinde durmuş bu çadırın hastanenin küçük bir modeli olarak algılanmaması gerektiğini, tıp folklorunun bir aşaması olarak görülmesinin daha uygun olacağını çeşitli delillerle açıklamıştır. Öztürk, burada hastanelerin Abbâsîlerde ortaya çıkmaya başladığını hemen akabinde de savaş veya yaygın hastalık gibi durumlarda seyyar hastanelerin kurulduğunu söylemektedir. Ayrıca Abbâsî Veziri Ali bin İsâ’nın dönemin yaygın hastalıklarıyla mücadele edilmesi için Sinan bin Sâbit başkanlığında bir ekip görevlendirdiğine vurgu yapmaktadır. Yazarın 
bu noktada Fuâd Sâlih es-Seyyîd'in Mu'cemü'l-Evâil adlı eserine atıfta bulunarak Ali bin İsâ'nın teşebbüsünü ilk seyyar hastane olarak gördüğü anlaşılmaktadır.

Birinci bölümün ikinci kısmında ise Öztürk, günümüzde hala önemli bir tartışma konusu olan ilk hastanenin ne zaman kurulduğu meselesini ele almıştır. Yazar, bu kısımda ilk olarak hastane karşılığı kullanılan bimâristan ve mâristan terimleri üzerinde durmaktadır. Ardından Emevî Halifesi Muâviye döneminde ilk hastanenin yapıldığı varsayımında bulunan kişilerin, kullanmış oldukları eserlerdeki malumatı yanlış anladıklarını izah etmektedir. Akabinde Mısır’n bir şehri olan Fustat'ta da bir hastanenin inşa edildiğini düşünen kişilerin bilgilerinin hatalı olduğunu burada bulunan yerin hekim evi olarak anlaşılması gerektiğini vurgulamaktadır. Son olarak o, birçok araştırmacı tarafından ileri sürülen Emevîler döneminde Halife Velîd b. Abdülmelik tarafından bir hastane yaptırıldığı görüşünü reddetmekte, tarih metinlerinde yer alan materyallerin cüzzamlıların ve körlerin bakımının yapılması şeklinde anlaşılması gerektiğini belirtmektedir. Nitekim Öztürk, bu konudaki hemen hemen bütün rivayetleri incelemiş ayrıca modern araştırmacıların pek çoğunun Ahmed Îsâ'nın eserine referans yapmalarından dolayı hatalı bir sonuca gittiklerini ileri sürmüştür. Son kısımda ise yazar, gerek kadim zamanlarda gerekse modern dönemlerde ilk hastanenin Abbâsîlerden önce inşa edildiğini iler sürenleri, bu kurumun ortaya çıkışında Hristiyan tesirinin olmadığını gösterme çabasının bir ürünü olarak görmektedir.

İkinci bölümde ilk hastanenin inşası olarak Hârûnürreşî́d'in yaptırmış olduğu Sa'îd hastanesini ele alan yazar, buranın en başta Sâ‘idî, Reşîl ve Kebîr isimleriyle anıldığını tespit etmektedir. O, ayrıca Sa'îd isminin sonradan ilave edilmiş olabileceğini hastanenin kurulmasına öncülük eden tabip ile ondan sonra gelen kişileri tespit etmeye çalışarak izah etmiştir. Ayrıca yazar hastanenin kurulması meselesinde sadece Arapça kaynaklara başvurmamış, bir Süryânî olan Tîmâsâvus'un mektubunu da kaynak göstererek bîmâristanın 790 yılında kurulmuş olabileceğini ileri sürmüştür. Öztürk, hastanenin Hârûnürreşîd döneminde kurulmasını iki sebebe bağlamaktadır. Bunlardan ilki tercüme faaliyetlerinin yoğunlaşması, ikincisi ise Hristiyan hekimlerin hastanenin kurulmasına öncülük etmeleridir.

Levent Öztürk, Hârûnürreşîd'in yaptırmış olduğu hastane ile aynı dönemde kurulmuş olan Bermekî hastanesini İslâm dünyasında vücuda getirilen ikinci hastane olarak ele almıştır. $\mathrm{O}$, Bermekî hastanesinin Hârûnürreşîd'in yaptırtmış olduğu hastaneden sonra inşa edildiğini temellendirerek Aydın Sayılı'nın varsayımlarını çürütmeye çalışmış ve Bermekî hastanesinde çalışan tabipleri zikretmiştir. O, ayrıca Bermekî ailesinin kısa bir zaman sonra devletteki gücünü yitirmesi ile beraber hastanenin de beş altı yıllık bir zaman aralığında kapandığını belirtmiştir.

Levent Öztürk, Abbâsîler döneminde on ikinci asra kadar kurulan hastaneleri tek tek incelemiş ve hakkında bilgi elde edebildikleri yerler için açıklamalarda bulunmuştur. $\mathrm{O}$, bu iki hastaneden ayrı olarak Abdullah $\mathrm{b}$. Tâhir hastanesi başlığı açmış fakat bu yerin mahiyetinin tam olarak tespit edilemediğini belirtmiştir. Meğâfir veyahut Meâfir hastanesinin de Abbâsîler döneminde Mısır'da yapıldığını fakat net bir zamanın şu anlık tespit edilemeyeceğini ifade etmiştir. Bedir hastanesini ele alan yazar, buranın Sâmerra döneminden sonra Bağdat'ta kurulduğuna değinmiştir. Ayrıca buranın kim tarafından yaptırıldığı hakkında problemlerin olduğunu belirten yazar bu konuya da açıklık getirip faaliyette bulunan kişinin Bedir el-Mu'tazıdî olduğunu aktarmıştır. Râzî'nin, Mu'tazıd döneminde Bağdat'a geldiği ve bu hastanede çalıştığı, Sinan bin Sâbit'in, hastanenin kurulmasından itibaren başhekim olduğu ve sonraki dönemlerde de birçok hastanenin kurulmasına katkı sağladığı verilen bilgiler arasındadır. Yazar akabinde Mekke, Medine ve Ali bin İsâ hastanelerinin mevcudiyeti üzerine bir araştırmada bulunmuş ve miladî onuncu asrın ilk yarısında çeşitli salgın hastalıklardan dolayı hastane yapımının çoğaldığını vurgulamıştır.

Seyyide hastanesi halife Muktedir-Billah'ın annesi Şağab Hatun tarafından Sinan bin Sâbit'in mihmandarlığında yaptırılmıştır. Hastanenin sorumlusu Sinan bin Sâbit'tir. Şağab Hatun hastanenin aylık 
gideri olarak da altı yüz dinar vermektedir. Sinan ayrıca halifenin kendisine de el-Bîmâristânü'l-Muktedirî́yi yaptırmış ve buranın da baş sorumluluğunu yürütmüştür. İbnü'I-Furât hastanesi de vezir íbnü'l-Furât elAkûlî tarafından miladî 911 yılında Alî bin Îsa’ya hasım olmasından dolayı inşa edilmiştir.

Cündîşâpûr hastanesi ilk İslâm fetihleri zamanında sulh yolu ile hâkimiyet altına alınmış ve varlığını uzun asırlar boyunca devam ettirmiştir. Okulda eğitim gören veya tabiplik yapan kişiler Abbâsîler döneminde halifelerin rahatsızlı̆ı̆nda yanında bulunmuş ileriki zamanlarda da ilk hastanelerin kurulmasında öncülük etmişlerdir. Rey hastanesinin ne zaman yapıldığı tam olarak bilinmese de Abbasîler döneminde varlığını sürdürmüş ve Râzî (ö. 313/925) burada başhekimlik görevinde bulunmuştur. Abbâsîler döneminde örnek olarak verdiklerimizden başka birçok hastanenin ne zaman kurulduğu, kimin tarafından kurulduğu ve kimlerin bu hastanelerde hizmet ettiği gibi meselelere değinilmektedir.

Levent Öztürk, çalışmasını kronolojik bir bağlama oturttuğu için ikinci devlet olarak Endülüs Emevîlerini (750-1100) inceleme konusu olarak ele almıştır. O, 750 ve 1100 yılları arasında Endülüs'te bir hastanenin olmadığını, en erken hastane kalıntılarının da on üçüncü asra tekabül ettiğini belirtmektedir. Endülüs'te hastalıkla ilgili tıbbi bilgilerin genelde ỉbrişim (ansiklopedik mahiyette tıp kitabı) türü eserlerden öğrenildiği, Endülüslü olup Bağdat'ta eğitim gören kişilerin ise sarayda imtiyazlı bir konumda olsa da hastane yapımıyla alakalı bir adımın olmadığını ileri sürmektedir.

Öztürk, bu devletler haricinde Ağlebîler (800-909), Tolunoğulları (868-905), îhşîîiler (935-969), Büveyhîler (932-1062), Fâtımîler (969-1100), Karahanlılar (840-1100), son olarak Selçuklular (1040-1100) döneminde inşa edilmiş olan hastaneleri incelemiştir. Bu devletler içerisinde yaptırılmış olan bîmâristanların nerelerde ve hangi zaman aralıklarında kuruldukları, varlığını sürdürüp sürdürmedikleri, gelirlerini nerelerden temin ettikleri, kapasitelerinin ne kadar olduğu gibi malumatı eldeki veriler nispetince irdelemiştir.

Öztürk, sonuç kısmında, ele almış olduğu çalışmanın genel bir özetini sunmuştur. Burada da kronolojik bir yol izleyerek ilk insanlık dönemlerinden itibaren sağlık hizmetinin verildiği yerlerden bahsederek on ikinci yüzyıla kadar gelmiştir. Ayrıca ekler kısmında mezkûr devletlerde yapılmış olan hastaneleri tablolar halinde kronolojik bir sıra ile sunarak okuyucunun metni daha iyi anlamasına olanak tanımıştır.

\section{Sonuç}

Incelemiş olduğumuz bu eser, son zamanlarda yaygın bir biçimde İslâm dünyasında ilk hastanenin Emevîler döneminde inşa edildiği savını tartışmaya açması, bu görüşü ileri sürenlerin delillerini çürütmeye çalışması bakımından tıp tarihi alanında yeni bir tartışma yaratacak, mevcut bilgilerimizi kökten değiştirecek iddialara sahip görünmektedir. Ayrıca Abbâsîlerden Karahanlılar’a pek çok devlet ve hanedanlık içerisinde henüz ele alınmamış birçok hastane hakkında bilgi sunması da eserin orijinal bir diğer özelliğidir. Tıp tarihi açısından Türkçe literatürde önemli ve ilk çalışma olarak ayrı bir değere sahip olduğunu düşündüğümüz bu eserin tıp tarihi meraklılarının ilgisini çekeceğini umuyoruz. 